\title{
The Fugal Structure as a Reflection of the Polyphonic Pattern of the World
}

\author{
Abir U. Igamberdiev \\ Department of Biology, Memorial University of Newfoundland, St. John’s, NL A1B3X9, Canada; E- \\ mail: igamberdiev@mun.ca, Tel.: +1-709-864-4567; Fax: +1-709-864-3018
}

Accepted:

\section{Introduction}

Music represents the knowledge about the wholeness and unity of the word. In contrast to other arts, music is prolonged and organized in time. It can be viewed as a reflection from the infinity (potential field) into the finite set of sounds. The potential field in music texts was analyzed by Arkadiev (1993) who suggested that music appears as a structuralized silence, and that the silent accents in music play even more important roles than its sounds. The potential field is always a contradictory set of possible realizations; therefore it is silent per se. This set is realized in the music creation as a process of the appearance of sounds that is organized in time. The most striking example of quasi-rationality of such a process is fugue where the musical composition becomes similar to mathematical creativity. The same pattern of realizations as in music appears in the quantum mechanical measurement where those histories become actualized that are consistent, and the condition of consistency becomes the basic prerequisite of the actual existence. Thus the whole world appears as symphonic, and its pattern includes polyphony as its fundamental background.

Mathematics and music were considered as similar arts in the Pythagorean philosophy. Music can be more rational in its structure in baroque and classicism or more irrational in romanticism. It may be rational in its form, but as a reflection of infinity it cannot be finitely countable. Mathematics deals with finite processes that are the limits of iteration of infinite processes. But because of the paradoxical properties of time (described in the Zeno's aporia “Achilles and Tortoise”), these limits can be realized within finite durations of time, which itself cannot be resolved by finite means. And without these paradoxes music may not exist. The limits of iteration are present in the musical structure. One of these limits is the golden section which can be considered as the limit of iteration in reflective measurements (Lefebvre 1990, 1995). Lefebvre (1995) has shown in the detail analysis that the golden section is important in the European musical tradition. 


\section{Fugal Reflection of the Logical and the Physical Realities}

For Pythagoras and Plato, the 'techne mousike' is a mathematical (from the modern point of view, we would rather say meta-mathematical) experience. The idea that music can govern over human, natural and divine forces situates music as a metaphysic discipline related to cosmology and social being. Pythagoras indeed was convinced in a kind of universal cosmic harmony; he thought that music is able to take us from the world of becoming into the world of being. This was later revived by Leibniz in the letter to Goldbach: "Musica est exercitium arithmeticae occultum nescientis se numerare animi" [Music is a hidden arithmetic exercise of the soul, which does not know that it is counting]. On the other hand, Aristotle analyzed music within the horizon of 'practical philosophy' contrary to Pythagoras: music intends to "produce” (poiesis) something which is related to the "ethical character', and has a cathartic (or cleaning) effect on the soul. In his views, music is more an ethical activity and less a pure mathematical creation.

The same context exists in relation to J.S. Bach and L. van Beethoven. I do not analyze here Mozart because his music aims to escape from such analysis. It images the divine link between the two realities, the logical and the physical, and somehow escapes the battle between nominalism and realism. Mozart represents such a wonderful unity that is usually easy to listen but very difficult to interpret. In J.S. Bach's music, the Logos governs the ideal world (of Pythagoras and Plato), and in Beethoven's music the Physis (the real world of Aristotle) exhibits itself, while Mozart represents that Elusive (fugacior in Latin), which unites them both and is personified as a Holy Spirit in the Christian tradition or as Eros in Plato's philosophy. Following Heraclitus, the same essence appears in the thought as Logos, in the world as Fire, and altogether as Cosmos.

Fugue is one of the most complicated, if not the most complicated, forms of music ever created. J.S. Bach practically invented fugue, and in the space of one work, "Die Kunst der Fuge", perfected it beyond any comparison. It is logical to compare Bach's die Kunst der Fuge and Beethoven's Grosse Fuge. Both can be considered as the greatest exercises of each composer. However Bach exercised in the area of Logos where he faced the impossibility to bring the conclusion to the final contrapunctus of die Kunst der Fuge. Beethoven's area is rather Physis or the embodiment of Logos in the immanent reality. J.S. Bach's music represents the internal creative logic of thought while Beethoven reflects and recreates the process of implementation of thought into the real world.

\section{Fugue and the Search of Semantic Closure}

It is important to say few words about the fugal structure to approach the problem of semantic closure. The expression of wisdom can be fugal (Grew, 1931) because the fugal structure bears the knowledge and the power together. In the motion to understand the world, J.S. Bach expressed the achievement of a meta-mathematical construction, while Beethoven analyzed the act of achieving. As a result, the two ideas (knowledge and power) in the end prove to be the one. Beethoven's fugues are all about Physis, i.e., they refer to the patterns of fitting together in the evolving network of nonequivalent observers, while J.S. Bach’s fugues are about Logos and refer to the contradictory structure of thought. In Beethoven's music, the fugue is a "feast of mind" according to Sviatoslav Richter - we would say, of the mind acting within the immanent physical space-time. 
This acting can be formulated as the problem of semantic closure of the world that includes the subject observing it and acting in it. Can the image of the world be produced that includes the observer as a part of the image? J.S. Bach's last opus shows that it is rather impossible to solve the problem of semantic closure after the inclusion of the observing subject in the field of Logos. But this problem is the basic challenge of the physical universe where it is perpetually and relationally being solved. Beethoven's greatest and rather negative answer is in Hammerklavier (the $29^{\text {th }}$ sonata, Die Grosse Sonata für Hammerklavier, op. 106). It is finished by the fugue imaging the world without the final semantic closure. This solution could be considered as final for other composers (as it appears with a stronger sense of negativity in the best musical compositions of the XX century), but Beethoven could not leave this open, i.e., he could not leave the world unresolved. Alternatively, die Grosse Fuge starts from the instant finding of the final solution of world's meaningful completeness and in the further development this solution is consistently analyzed and affirmed as a free solution of the existence of the habitable, perceptible and cognizable world.

The substantial difference between the worlds of mathematics and physics is not trivial. The view exists that everything that can be computed may be present in the physical Universe (Tegmark, 2007). However, in real physical world, only few solutions are realized as consistent histories (Igamberdiev, 2007). The mathematical reality can be referred to Logos ( as Physis $(\varphi v \sigma i \varsigma)$ in terms of Greek philosophy. The relation between Logos and Physis is based on a fragile correspondence, where Logos is interpreted in Physis, while Physis becomes in certain limits and in its temporal frames non-contradictory by holding Logos in it. Thus we have the basic triadic structure, where Logos signifies Physis, Physis is signified by Logos, and their relation is an Interpretant that in a particular case can be represented by the acting observer. This all is united in a triadic structure which is reflected in the Peircean sign (Peirce, 1955). It includes two material causes (between the object and the sign-representamen, and between the sign and the interpretant).

To exist, the world should be closed by including potentially its observer. It forms a closed structure where the process of reflection makes it complete. But this completed structure being physical can exist for a limited period of time in which it can hold paradox and which separates contradictory statements. After that time is passed, “the global system's failure” takes place (Rosen, 1978). The Divine completion in the infinity in the physical world is reflected in the temporal completion of a living being (autopoietic system). This temporal completion has not yet received its final formalized expression in metamathematics but it was described by informal means in the Peircean semiotics.

\section{Grosse Fuge and the Future Development of Music}

Glenn Gould considered the Grosse Fuge as "the ultimate inductive piece" which is "the most farsighted piece of music ever written”. The Grosse Fuge expresses the "striving against near-impossible odds” as Richard Wigmore mentioned. These near impossible odds are kept in the structure in a way that they become conquered in the consistent development of the initial fugal structure. This is the great approach and it is indeed different from the development that we observe in the XX century. The $\mathrm{XX}$ century came to the understanding of greatness of this composition that was almost completely absent in the XIX century. But the XX century music, while having accepted the odds, also accepted the absence of the escape from them. Arnold Schoenberg heard it as a premonition of atonality, a call 
for freedom from convention. ("Your cradle was Beethoven’s Grosse Fuge," Oskar Kokoschka once said to Schoenberg.)

Dodecaphony came as an alternative structure for music based on these odds included in its basis. Especially in the music of Anton Webern, we see the ultimate metalogical structure for this, and this structure simulates nothingness as the basis for the world. The most dodecaphonic Shostakovich quartets, the $12^{\text {th }}$ (op. 133) and the $13^{\text {th }}$ (op. 138), are influenced by Grosse Fuge: they do not bear the religious revelation of Grosse Fuge but realize the reflection into nothingness. In the $12^{\text {th }}$ Quartet, the “optimistic" final looks as somehow externally exposed. In the $13^{\text {th }}$ Quartet even this is absent, and the nothingness bears its own solution. The cathartic revelation comes only from sensing of the fundamental substantial absence.

On the other hand, the attention of Dmitry Shostakovich to Grosse Fuge comes from the embodiment of his music into the real world, which is similar to Beethovenian. The evil in the real world is much more powerful but not omnipotent in Shostakovich's music; and it can be overcome at least via ultimate preservation of the dignity by the suffering individual soul, and so there is a possibility of a way that can lead to the basic solution overcoming evil. It is important to mention that Shostakovich planned to write the $16^{\text {th }}$ Quartet which should contain a big fugue as a finale (mentioned in his correspondence with Krzysztof Meyer).

In this tendency and desire, Shostakovich is similar to Beethoven and more different from Alfred Schnittke. Die Grosse Fuge is quoted in Alfred Schnittke's Third String Quartet, but in the music of Schnittke the infernal reality is rather more like a negative reflection of the Cosmos and in this regard it is infinite, so there is no way of escaping from it. The great belief in the possibility of the ultimate escape to overcome incompleteness accompanies the development of human civilization, although no final solution can be achieved in this profound movement. But the formulation of substantiality of searching for such solution is a great desire by itself that is reflected in the highest achievements of art, science and philosophy.

\section{Conclusion}

The attempt of Beethoven needs a profound understanding of its chronotope (the term of M.M. Bakhtin who by himself viewed the world as polyphonic). The monologic way of perceiving cognition and truth is only one of the possible ways. It arises only where consciousness is placed above existence (Bakhtin, 1984). Non-equivalent observers form an uneven continuum of the visible world and the final truth of this world arises above the individual truths of them via the inclusion of these truths into the final ultimate solution.

L. van Beethoven suggested a solution within the world of freedom having a kind of semantic completeness. J.S. Bach searched for a Pythagorean solution of completeness of the Universe that includes self... and broke into silence. Beethoven's Grosse Fuge gives us an example of the exercise that ultimately leads to overcoming all near-impossible odds. It substantiates the world and leads us to finding the explanation to it. This is the only complete example of the music and maybe of the whole art that represents the world where the solution for its semantic closure is found, at least in the context of exercise having the balance of strict rules and extensive freedom. Grosse Fuge in certain sense is the only example of non-utopic achievement of completeness of the real world. The solution outlined in the Grosse Fuge requires its profound and congruent meta-mathematical analysis, in the same way as 
the Gilbert's problems and the Gödel's theorems are congruent to J.S. Bach's universe. Approaches to the logic of creative construction were developed in the intuitionistic mathematics by L.E.J. Brower, in the topoic logic, and in C.S. Peirce's semiotics and algebra. The latter introduces the ultimate reflective statement that makes the mathematical construction complete. The substantiation of this completeness is a great task, which is in fact a substantiation of the link connecting mathematical equations to the physical world. In all cases, the enclosing element is difficult to formulate. This element represents the infinite interpretant embodied as a finite sign. Beethoven's Grosse Fuge in its structure explicitly contains this interpretant and therefore represents the desire of the ultimate great solution that remains in the solitude among the greatest buildings of the human civilization, and in this solitude reflects another solitary peak of J.S. Bach’s die Kunst der Fuge.

\section{References}

1. Arkadiev, M.A. Structures of Time in New European Music (An essay of phenomenological study). Biblos, Moscow, 1993.

2. Bakhtin, M.M. Problems of Dostoevsky's Poetics. Edited and translated by Caryl Emerson. University of Minnesota Press, Minneapolis, 1984.

3. Grew, S. Beethoven’s “Grosse Fuge”. The Musical Quarterly 1931, 17, 497-508.

4. Igamberdiev, A.U. Physical limits of computation and emergence of life. Biosystems 2007, 90, 340-349.

5. Lefebvre, V.A. The fundamental structures of human reflexion. In: American University Studies, Series 8, Psychology, vol. 17, Harvey Wheeler (ed.), pp. 5-70. Peter Lang, New York, 1990.

6. Lefebvre, V.A. The anthropic principle in psychology and human choice. Psycoloquy 1995, 6, 29.

7. Peirce, C.S. Collected Papers of Charles Sanders Peirce, vols. 1-8 (C. Hartshorn, P. Weiss, A.W. Burks, eds.). Harvard University Press, Cambridge, 1931-1958.

8. Rosen, R. Feedforwards and global system failure - general mechanism for senescence. Journal of Theoretical Biology 1978, 74, 579-590.

9. Tegmark, M. The Mathematical Universe. Foundations of Physics 2007, 38, 101-150.

(C) 2015 by the author; licensee MDPI and ISIS. This abstract is distributed under the terms and conditions of the Creative Commons Attribution license. 